\title{
Is it pain if it does not hurt? On the unlikelihood of insect pain
}

\author{
Shelley A. Adamo
}

\begin{abstract}
Whether insects (Insecta) have the subjective experience of pain is difficult to answer. Recent work in humans demonstrated that the experience of pain occurs due to the activation of a "pain network" that integrates nociceptive sensory information, memory, emotion, cognition, and self-awareness. In humans, the processing of nociceptive sensory information alone does not produce the subjective experience of pain. Insect nociception is processed largely in parallel in two higherorder areas in the brain: the mushroom bodies and the central complex. There is little evidence of a coordinated pain network that would integrate these two areas with each other along with other traits thought to be important for a pain experience in humans. However, it is difficult to exclude the possibility that insects could have a modest pain experience using a less integrated neural circuit. This possibility seems unlikely, however, because even a modest experience would require some neuronal investment. It is unclear whether insects would benefit from such an investment. Recent work in artificial intelligence suggests that relatively simple, cost-efficient circuits can produce adaptive behaviours without subjective experience. Given our current understanding of insect behaviour, neurobiology, and evolution, the likelihood that insects experience pain is low.
\end{abstract}

\section{Introduction}

Recent debate over whether lobsters (Decapoda: Nephropidae) feel pain has heightened interest in the question of whether insects (Insecta) feel pain. Concerns about lobsters have resulted in new regulations about their transport and containment, on the assumption that they experience distress (Browman et al. 2018). Should we have the same concerns about insects? Although all animals (Animalia) deserve our respect (e.g., see Mather 2011; Adamo 2016), not all animals may experience pain.

Pain is a negative subjective experience (Allen et al. 2005) that is complex and multifaceted (Garcia-Larrea and Jackson 2016). It encompasses feelings such as discomfort and despair. It differs from nociception, which is the ability to sense damaging stimuli (Allen et al. 2005). All organisms have some form of nociception, even Bacteria (Berg 1975). It is possible to have nociception without pain (Hardcastle 1997).
People with complete spinal transection still exhibit nociceptive reflexes below the level of the injury (e.g., flexion of the ankle in response to an electric shock of the foot), but these reflexes occur without pain (Andersen et al. 2004). Therefore, exhibiting short-term or long-term behavioural responses to harmful stimuli does not mean that an animal feels pain. The behavioural change could be part of a response to nociception. Because pain is a private, subjective experience, it is difficult to determine which animal species experience pain. Some philosophers suggest using the "argument by analogy" to answer this question (e.g., Allen et al. 2005). This method compares the behaviour and neurobiology of the animal in question with that of humans, who are known to feel pain. If the behaviour of an animal is consistent with how humans behave when in pain, and the animal has the appropriate neuroanatomical areas, then it is concluded that the animal would

Received 20 March 2019. Accepted 21 May 2019. First published online 20 August 2019.

S.A. Adamo, Department of Psychology and Neuroscience, Dalhousie University, Halifax, Nova Scotia, B3H 3X5, Canada

Corresponding author (e-mail: sadamo@dal.ca)

Subject editor: Hervé Colinet

doi:10.4039/tce.2019.49 
experience some form of pain. However, insect behaviour and neurobiology differ substantially from that of humans, making it difficult to use the argument by analogy. Nevertheless, it is possible to consider more broadly what behavioural and neurobiological attributes we would expect in an organism that experiences pain (Sneddon et al. 2014).

\section{Behaviour}

Insects respond to damaging stimuli with a variety of avoidant behaviours (Eisemann et al. 1984). Moreover, noxious stimuli, such as electric shock, promote learning (e.g., Waddell and Quinn 2001), demonstrating that nociception is motivating in insects. Insects can also inhibit nociceptive behaviour, depending on the context. For example, some insects exhibit sexual cannibalism; the male allows the female to eat him during mating (e.g., Cyphoderris strepitans Morris and Gwynne (Orthoptera: Prophalangopsidae); Sakaluk et al. 1995). Noxious stimuli (e.g., a pinch) can have long-lasting effects on behaviour (e.g., McMackin et al. 2016). Therefore, the insect response to damaging stimuli is far more complex than a reflex. Additionally, behavioural studies have shown that insects have impressive learning abilities (Perry et al. 2017). Social insects, for example, show sophisticated forms of behavioural plasticity that appear similar to observational learning (Alem et al. 2016), numeracy (Skorupski et al. 2018), and having complex emotional states (Perry and Baciadonna 2017). Social insects are also rightly famous for their communication abilities (e.g., Dyer et al. 2002). These phenomena raise the possibility that insects may have neural circuits that are capable of subjective experience.

However, some behaviour that denote advanced cognitive or emotional capacity in humans are mediated by simpler mechanisms in insects (e.g., Alem et al. 2016). For example, a phenomenon known as "learned helplessness" has been used in dogs (Canis lupus familiaris Linnaeus (Carnivora: Canidae) and other Mammalia; Maier and Watkins 1998) as an animal model of depression (Seligman and Maier 1967). Learned helplessness is induced by exposing dogs to unavoidable shocks in a training cage. After this experience, dogs have difficulty learning that a flashing light warns them of a shock that they can avoid by jumping over a barrier. A dog that has never been shocked learns this lesson quickly. Insects also exhibit learned helplessness (e.g., Batsching et al. 2016). In learned helplessness studies on insects, one group of insects is able to escape an electric shock, while the other group cannot. The group that cannot escape the shock shows a reduced ability to learn to avoid subsequent shocks (e.g., Batsching et al., 2016). However, in insects (e.g., Drosophila melanogaster Meigen (Diptera: Drosophilidae)), learned helplessness is very context-specific and does not appear to generalise to other behaviours (Batsching et al. 2016). In mammals, learned helplessness leads to a reduction in a range of motivated behaviours (Maier and Watkins 1998), which is why it has been considered an animal model for depression. In insects, even a cockroach (Periplaneta americana (Linnaeus) (Blattodea: Blattidae) leg attached to a thoracic ganglion can show plasticity operationally similar to learned helplessness (Eisenstein and Carlson 1997). Either a ganglion of about 1000 neurons is capable of depression, or learned helplessness can occur without a psychological experience in insects. In another example, male courtship behaviour in D. melanogaster is modulated by both internal and external cues (Ellendersen and von Philipsborn 2017). However, neural stochasticity plays a role in producing variable male courtship behaviour (Zhang et al. 2018), preventing D. melanogaster from becoming a "reflex machine" without using complex neural processes.

Other aspects of insect behaviour are incongruent with mammalian pain behaviour. Although larval insects show sensitisation of nociception after damage that resembles both hyperalgesia (Walters et al., 2001; Babcock et al. 2009) and allodynia (Babcock et al. 2009; McMackin et al. 2016), adult insects of a number of species will walk on damaged limbs (Eisemann et al. 1984). Some insects will continue to feed while being eaten themselves (Eisemann et al. 1984). Damaged cockroaches (S.A.A., personal observation) and Mormon crickets (Anabrus simplex Haldeman (Orthoptera: Tettigoniidae) (Lockwood 2012) will consume their own internal organs. They appear to respond to the protein stimulus of their 
own guts and eat them, even if they are not fooddeprived.

\section{Neurobiology of nociception and pain}

Differentiating between nociception and pain requires human subjects, because humans can communicate their subjective experience. Humans have sensory neurons (nociceptors) that respond to damaging stimuli (Purves et al. 2012). Nociceptive sensory information follows well-studied tracts through the spinal cord and into the brain (Purves et al. 2012). Intracranial electrical recordings and noninvasive imaging studies demonstrate that there is a difference between nociception and pain (Chatelle et al. 2016). Humans initially process incoming nociceptive stimuli preconsciously in two parallel pathways that assess the sensory and emotional aspects of pain (Bastuji et al. 2018; Hagiwara et al. 2018). These pathways consist primarily of subcortical regions; the thalamus is a key area in the sensory pathway, while the amygdala is important for the emotional processing pathway (Bastuji et al. 2018). From the thalamus, nociceptive stimuli are transferred to a cortical nociceptive network consisting of primary and secondary somatosensory cortices, as well as the posterior insula ( $\mathrm{Lu}$ et al. 2016; Bastuji et al. 2018; Garcia-Larrea and Bastuji 2018). The activation of this nociceptive network, which includes both cortical and subcortical structures, is not sufficient for the subjective experience of pain (Bastuji et al. 2016; Garcia-Larrea and Bastuji 2018). Nevertheless, the activation of the nociceptive network can produce long-lasting effects on behaviour (Garcia-Larrea and Bastuji 2018). The perception of pain occurs a fraction of a second after activation of the nociceptive network with the activation of a "pain network"; i.e., circuits that combine the sensory and emotional aspects of nociception along with other factors such as memory (Garcia-Larrea and Bastuji 2018). This network includes the activation of sensorimotor and fronto-parieto-insular cortical areas (Garcia-Larrea and Bastuji 2018). The full sensation of pain occurs when these regions are joined by activity in the posterior cingulate and medial temporal cortical areas (Garcia-Larrea and Bastuji 2018). These conclusions were based on studies (e.g., Bastuji et al. 2016) in which patients with intracranial electrodes were given nociceptive-specific stimuli (e.g., laser pulses). The exact timing of activity in different brain regions was recorded and compared with the timing of a voluntary muscle movement that patients were asked to make as soon as they felt pain. The time required to make the movement was taken into account to determine the time when pain was perceived (Bastuji et al. 2016). Activity in the insula cortex and the amygdala occurred more than $120 \mathrm{~ms}$ before the earliest motor reaction, suggesting that this brain activity was occurring prior to conscious awareness (Bastuji et al. 2016). These results suggest that the subjective experience of pain is the product of a complex and dynamic neural network, although a definitive pain "connectome" is still missing (see Mouraux and Iannetti 2018). Nevertheless, the evidence in humans shows that pain is not created by activity in a single brain area (Bastuji and Lavigne 2016; Chatelle et al. 2016; Garcia-Larrea and Bastuji 2018), and this is likely true in other mammals as well (e.g., laboratory mice (Mus musculus Linnaeus; Rodentia: Muridae); Corder et al. 2019).

Human studies show that pain experience requires the combination of different inputs (e.g., emotional, sensory, cognitive), and that this combination occurs in cortical structures (GarciaLarrea and Bastuji 2018). However, other animals could use different neural structures to create a subjective experience of pain. Could insect brains support a pain network? Insects clearly have the neural machinery for nociception. They have multimodal nociceptors (Guo et al. 2014) that tile the body wall (Grueber et al. 2001). Just as mammalian nociceptors send information to the brain via dorsal horn neurons in the spinal cord (Purves et al. 2012), insect nociceptors synapse onto neurons that reach the brain (e.g., larval D. melanogaster; Gerhard et al. 2017). Although the entire nociceptive pathway has not yet been delineated in any insect, it is known that nociceptive information is processed in two higher-order integratory areas, the mushroom bodies (Waddell 2013; Konig et al. 2018) and the central complex (Hu et al. 2018). These two areas are among the most complex in the insect brain, and are key for navigation, learning, memory, and other complex cognitive tasks (Barron and Klein 2016; Kinoshita and Homberg 2017). A peripheral 
electric shock activates neurons in both the fan-shaped body of the central complex, and the mushroom bodies in D. melanogaster ( $\mathrm{Hu}$ et al. 2018). The fan-shaped body is necessary for both innate and conditioned escape behaviours in response to nociceptive stimuli ( $\mathrm{Hu}$ et al. 2018). Unfortunately, the details of how nociceptive sensory information reaches the fan-shaped body, and how the fan-shaped body activates its motor targets, remain unknown (Hu et al. 2018). Nociceptive information (i.e., electric shock) also activates dopaminergic cells in the protocerebrum, and these neurons encode the saliency of a sensory input, i.e., whether it is rewarding or aversive (Waddell 2013). These dopaminergic neurons innervate both the mushroom bodies and the central complex (Galili et al. 2014). The dopaminergic input to the mushroom bodies is critical for nociception to have reinforcing effects and stimulate learning (Waddell 2013).

The most striking difference between the central processing of nociception in insects compared with that in mammals is the apparent lack of a higher-order network combining brain regions involved in nociception (e.g., the mushroom bodies and central complex). Both the mushroom bodies (Aso et al. 2014a, 2014b) and the central complex (Franconville et al. 2018) have few output neurons, restricting the type of information they can transmit (Collett and Collett 2018; Franconville et al., 2018). For example, although the mushroom bodies can have 170000 intrinsic neurons (e.g., in honey bees - Apis mellifera Linnaeus (Hymenoptera: Apidae)) and have a complex neural architecture (Aso et al. $2014 a, 2014 b$ ), the number of output neurons is three orders of magnitude lower, about a few hundreds in honey bees (Peng and Chittka 2017) to $<100$ in other insects (Aso et al. 2014a, 2014b). Similarly, the central complex is a densely recurrent sensorimotor hub, but it has few output neurons (Franconville et al. 2018). The central complex is connected to a limited number of other brain regions (Franconville et al. 2018), while the mushroom bodies are connected to neuropils across the brain (Aso et al. 2014a, 2014b). This reduction in dimensionality (i.e., few neuronal outputs) is also observed in some mammalian subcortical brain structures. For example, the mammalian basal ganglia, which carry out some of the same tasks as the insect central complex, also demonstrate a similar dimension reduction (Fiore et al. 2015). However, this degree of dimension reduction is not a prominent feature of the cortical areas important for producing the pain network (e.g., prefrontal cortex; Fuster 2001). In humans, white matter tracts comprise $47 \%$ of total cortical mass (grey + white matter), demonstrating considerable investment in network capacity (Herculano-Houzel et al. 2010). Data from laboratory mouse (Oh et al. 2014), macaque (Simia inuus Linnaeus (Primates: Cercopithecidae)) (Markov et al. 2014), and human (Yeh et al. 2018) suggest that cortical areas are well connected in mammals.

Not only do mushroom bodies and the fanshaped body have few output neurons, there are no direct connections between them (Pfeiffer and Homberg 2014; Collett and Collett 2018; Hu et al. 2018), and they are not in the same hub of interconnected neuropils (Chiang et al. 2011; Shih et al. 2015). The lack of direct connections between these two important information integration centres in the insect brain raises question about how insects perform cognitive tasks (Collett and Collett 2018). For example, during navigation, the lack of a major connecting pathway between these two areas suggests that the mushroom bodies and central complex work in parallel, as opposed to working together as part of an integrated network (Collett and Collett 2018). In ants (Hymenoptera: Formicidae), this organisation suggests that during navigation, ants switch back and forth between using landscape memories (stored in the mushroom bodies) and celestial cues (stored in the central complex) to find their way home (Collett and Collett 2018). Collett and Collett (2018) postulate that the mushroom bodies transfer an attraction signal only to the central complex via a still unknown indirect pathway; this organisation reduces the amount of integration required between the two areas for accurate navigation. Nociception appears to be analysed in the same way, with parallel sensory inputs processed separately by the mushroom bodies and central complex (Hu et al. 2018).

In humans, pain perception requires the integration of the parallel sensory and emotional pathways that process nociceptive information, as well as the integration of this combined input with other inputs, such as from areas important for memory and cognition (Garcia-Larrea and Bastuji 2018). 
It is this integrative step that seems to be missing in insects. Insects have something like a nociceptive network, with nociception integrated in parallel in different brain regions, but they do not appear to have a pain network that integrates nociception processing across brain areas with higher-order functions. A similar conclusion has been suggested for Mollusca (Key and Brown 2018).

However, there is a great deal we do not know about nociception, even in the best studied insect, D. melanogaster (Hu et al. 2018). For example, both the mushroom bodies and the fan-shaped bodies are strongly connected to neuropils in the superior protocerebrum. The function of the superior protocerebrum is poorly understood (Strausfeld 2012). Although there is no evidence that nociceptive information is integrated in this brain region, it has not been well studied, and may play a larger role in nociception than is currently appreciated. There are also other areas of convergence (see van Swinderen 2005); for example, some mushroom body output neurons have axon terminals in the same region that contain the dendrites of neurons projecting to the fan-shaped body (Aso et al. 2014b). Although the central complex has few direct connections to other brain areas, it is indirectly connected to many of them (Hanesch et al. 1989). Therefore, there are connections between the mushroom bodies and the central complex, but they are indirect and mediated by few neurons. Studies on whole-brain networks in the insect (e.g., Yap et al. 2017) should help clarify our understanding of nociceptive processing. Such studies may demonstrate that there is more integration of nociceptive processing in insects than is currently thought.

Given the growth in our understanding of the neurobiology of pain in humans (e.g., GarciaLarrea and Bastuji 2018) and nociception in insects (e.g., Hu et al. 2018) in the last two years, it is not surprising that an earlier paper (Barron and Klein 2016) was more optimistic about insects having subjective experiences such as pain. Their conclusion was based, in part, on an earlier paper (Merker 2007) that argued that subcortical areas in humans were both necessary and sufficient for subjective experience. However, a decade later, the consensus appears to be that a complex neural ensemble that includes cortical areas is required for the subjective experience of pain in humans (Garcia-Larrea and Bastuji 2018).

\section{Evolutionary perspective}

Insects are unlikely to invest in the neural machinery required to feel pain unless there is an evolutionary advantage in doing so (Adamo 2016). Whether pain would be an advantage depends on whether the fitness benefits would outweigh the costs.

\section{Costs of having the subjective experience of pain}

Brains of all animals appear to be organised to minimise wiring costs (Arnatkeviciute et al. 2018; Liang et al. 2018). Large-scale integration of information across a brain is not cheap (Collin et al. 2014; Liang et al. 2018). High interconnectedness results in high levels of wiring volume, leading to high metabolic energy use (Collin et al. 2014). The pain network identified by Garcia-Larrea and Bastuji (2018) requires extensive (i.e., expensive) wiring. Insects have modest connections across brain regions, possibly because of the high cost of large neurons (Chittka and Niven 2009). Moreover, small insect brains may not provide the room required for the parallel and serial processing pathways (Chittka and Niven 2009) needed for a pain network. Given the current hypotheses of what is required for the subjective experience of pain (Garcia-Larrea and Bastuji 2018), the sparser interconnections within the insect brain may be unable to support pain perception.

In humans, subjective experience appears to require the investment of both additional neurons as well as additional wiring (Garcia-Larrea and Bastuji 2018). But how many neurons are needed for a minimal subjective experience of pain? Would 100 neurons be sufficient? In the lobster, Homarus americanus Milne-Edwards (Decapoda: Nephropidae), approximately 30 neurons are dedicated to maintaining two rhythms in the digestive tract (i.e., the stomatogastric ganglion; Marder and Bucher 2007). It is possible that subjective experience requires only two or three times as many neurons as stomach churning, but this seems unlikely. Even if subjective experience requires only 100 additional neurons, this would increase the cost of the brain by $0.1 \%$ in insects such as 
D. melanogaster that have about 100000 neurons in their brain (Zheng et al. 2018). Neurons are energetically expensive cells (Niven 2016). In both vertebrates and invertebrates, the nervous system consumes a significant portion of the energy budget of the animal (Niven and Laughlin 2008). Therefore, the increase in neural investment needed to produce the subjective experience of pain in insects would probably lead to a reduction in other traits such as reproduction.

However, neurons do not act alone, but as part of neural circuits. These circuits are dynamic, and an individual neuron can participate in more than one circuit (Marder et al. 2015). Insect nervous systems share neurons across circuits (Niven and Chittka 2010). If the neurons needed to experience pain were shared with other circuits, then the costs could be reduced. However, they would not be zero. The insect brain squeezes a wide range of cognitive tasks out of a small number of neurons, and neurons are already "multitasking" (Chittka and Niven 2009; Vogt et al. 2014). Computational models suggest that as neurons participate in more tasks, the performance of the network eventually degrades (Caruana 1997). Moreover, regardless of the number of neurons required for subjective experience, there would be additional costs due to the neuronal wiring needed to create the appropriate network. Therefore, although the subjective experience of pain is an emergent property of a neural network, the ability to experience pain is not cost-free.

Even if only a few additional neurons are needed for a very modest pain experience, every neuron an insect adds to its brain is proportionately more expensive than the cost of adding an additional neuron to the human brain (about one million times more expensive for D. melanogaster). Nevertheless, a high cost does not prevent a trait from evolving if the benefits outweigh the costs.

\section{Benefits of having the subjective experience of pain}

The standard argument for the value of pain is that it aids animals in making adaptive behavioural choices (Sneddon et al. 2014). In other words, it prevents insects from becoming mere "reflex machines". However, recent advances in artificial intelligence suggest that the subjective experience of pain is not necessary to achieve these benefits.
Robots can now be designed with "emotional architecture" that allows them to adapt their behaviour to changing environments (Dominguez et al. 2017). Negative emotions can be programmed to have long-lasting effects on the behaviour of a robot (Lee-Johnson and Carnegie 2010). These robots display the same or similar behaviours as those that have been used as evidence that insects have subjective experiences. For example, honey bees become less sensitive to positive stimuli and more sensitive to negative stimuli after shaking (i.e., ambiguous stimuli are more likely to be rejected; Bateson et al.2011). Although interpreted as an emotional response in honey bees, "emotional" robots show a similar phenomenon. For example, when programmed to have both feeding and survival goals, "food" became motivationally ambiguous in the presence of an artificial predator (Parisi and Petrosino 2010). When predator cues were present, the robot would accept only highquality food, avoiding the low-quality food that it would normally accept when predator stress was absent. A robotic rat has been programmed to feel "discomfort" when wet, providing it with a motivational drive (Ames et al. 2012). This robotic rat can learn to solve a Morris water maze, just like a real laboratory rat (Rodentia: Muridae) (Ames et al. 2012). The robot rat is "rewarded" by the lack of discomfort, similar to pain relief learning in D. melanogaster (Yarali et al. 2008). Robots can also exhibit pain-like behaviour that is more like our own than any insect (Stiehl et al. 2004). Robots can have flexible responses to damaging stimuli (i.e., modifiable pain responses; Matsunaga et al. 2005). Artificial intelligence-generated characters can respond to simulated damage with limps and wound guarding (e.g., Fallout 4; www.youtube.com/watch? $=$ Znn1EwpfOgA). Robots are also capable of observational learning (Reggia et al. 2018). These abilities suggest that subjective experience is not required for complex, motivated behaviour. Robots and computer simulations show that relatively simple, costefficient circuits can produce adaptive behaviours (e.g., Parisi and Petrosino 2010). Moreover, our partial understanding of the central neural circuits mediating nociceptive behaviour in D. melanogaster (e.g., Hu et al. 2018) suggests that subjective experience is not required to explain the adaptive behaviour of $D$. melanogaster to damaging stimuli (also see Gutfreund 2017). In other words, present models 
can explain how nociception can motivate learning (Waddell 2013; Hu et al. 2018) without requiring the subjective experience of pain. If insects can produce complex, motivated behaviour without paying for the additional neuronal resources required for experiencing pain, then evolution should select this cheaper option.

\section{Caveats}

An unfortunate side effect of using the human brain as the gold standard for the neural requirements for subjective experience means that all other brains are likely to be found wanting simply because they are different. It is possible that insects have a more modest experience using a relatively basic network, although, in humans, a less complex network results in a nociceptive network that appears to be devoid of the subjective experience of pain. However, studies in humans do not illuminate the circuitry required for a minimal subjective experience. The subjective experience of pain is unlikely to be an all-or-none phenomenon. But this issue forces us to consider what we would accept as a subjective experience of pain. What if it was devoid of emotional content? What if cognition is not involved? If insects have any type of subjective experience of pain, it is likely to be something that will be very different from our pain experience. It is likely to lack key features such as distress, sadness, and other states that require the synthesis of emotion, memory, and cognition.

\section{Conclusion}

We can never know with certainty whether insects feel pain, but given our current understanding of insect behaviour, neurobiology, and evolution, the likelihood is low. The main issue is not even the small number of neurons in insects (several orders of magnitude less than in humans; Herculano-Houzel 2012). The more important difference is the lack of connections between relevant brain areas. If the subjective experience of pain is produced by a network composed of brain regions that integrate sensory information processing, emotions, cognition, and memory, then it does not appear that insects have their relevant areas wired up in this way.

\section{Acknowledgements}

I thank T. Trappenberg for helpful discussions.

\section{References}

Adamo, S.A. 2016. Do insects feel pain? A question at the intersection of animal behaviour, philosophy and robotics. Animal Behaviour 118: 75-79. https:// doi.org/10.1016/j.anbehav.2016.05.005.

Alem, S., Perry, C.J., Zhu, X.F., Loukola, O.J., Ingraham, T., Sovik, E., and Chittka, L. 2016. Associative mechanisms allow for social learning and cultural transmission of string pulling in an insect. Public Library of Science Biology, 14: e1002564. https://doi.org/10.1371/journal.pbio.1002564.

Allen, C., Fuchs, P.N., Shriver, A., and Wilson, H.D. 2005. Deciphering animal pain. In Pain: new essays on its nature and the methodology of its study. Edited by M. Aydede. Massachusetts Institute of Technology Press, Cambridge, Massachusetts, United States of America. Pp. 351-366.

Ames, H., Mingolla, E., Sohail, A., Chandler, B., Gorchetchnikov, A., Leveille, J., et al. 2012. The animat new frontiers in whole brain modeling. Institute of Electrical and Electronics Engineers Pulse, 3: 47-50. https://doi.org/10.1109/ mpul.2011.2175638.

Andersen, O.K., Finnerup, N.B., Spaich, E.G., Jensen, T.S., and Arendt-Nielsen, L. 2004. Expansion of nociceptive withdrawal reflex receptive fields in spinal cord injured humans. Clinical Neurophysiology, 115: 2798-2810. https://doi.org/10.1016/ j.clinph.2004.07.003.

Arnatkeviciute, A., Fulcher, B., Pocock, R., and Fornito, A. 2018. Hub connectivity, neuronal diversity, and gene expression in the Caenorhabditis elegans connectome. Public Library of Science Computational Biology, 14: e1005989. https:// doi.org/10.1371/journal.pcbi.1005989.

Aso, Y., Hattori, D., Yu, Y., Johnston, R.M., Iyer, N.A., Ngo, T.T.B., et al. 2014a. The neuronal architecture of the mushroom body provides a logic for associative learning. Elife, 3: e04577. https:// doi.org/10.7554/eLife.04577.

Aso, Y., Sitaraman, D., Ichinose, T., Kaun, K.R., Vogt, K., Belliart-Guerin, G., et al. 2014b. Mushroom body output neurons encode valence and guide memorybased action selection in Drosophila. Elife, 3: e04580. https://doi.org/10.7554/eLife.04580.

Babcock, D.T., Landry, C., and Galko, M.J. 2009. Cytokine signaling mediates uv-induced nociceptive sensitization in Drosophila larvae. Current Biology, 19: 799-806. https://doi.org/10.1016/j.cub.2009. 03.062 .

Barron, A.B. and Klein, C. 2016. What insects can tell us about the origins of consciousness. Proceedings of the National Academy of Sciences of the United States of America, 113: 4900-4908. https://doi.org/ 10.1073/pnas.1520084113. 
Bastuji, H., Frot, M., Perchet, C., Hagiwara, K., and Garcia-Larrea, L. 2018. Convergence of sensory and limbic noxious input into the anterior insula and the emergence of pain from nociception. Scientific Reports, 8: 13360. https://doi.org/10.1038/ s41598-018-31781-z.

Bastuji, H., Frot, M., Perchet, C., Magnin, M., and Garcia-Larrea, L. 2016. Pain networks from the inside: spatiotemporal analysis of brain responses leading from nociception to conscious perception. Human Brain Mapping, 37: 4301-4315. https:// doi.org/10.1002/hbm.23310.

Bastuji, H. and Lavigne, G. 2016. Pain perception during sleep. In Pain and the conscious brain. Edited by L. Garcia-Larrea and P.L. Jackson. Lippincott Williams and Wilkins, Philadelphia, Pennsylvania, United States of America. Pp. 61-74.

Bateson, M., Desire, S., Gartside, S.E., and Wright, G.A. 2011. Agitated honeybees exhibit pessimistic cognitive biases. Current Biology, 21: 1070-1073. https://doi.org/10.1016/j.cub.2011.05.017.

Batsching, S., Wolf, R., and Heisenberg, M. 2016. Inescapable stress changes walking behavior in flies learned helplessness revisited. Public Library of Science One 11: e0167066. https://doi.org/10.1371/ journal.pone. 0167066 .

Berg, H.C. 1975. Chemotaxis in bacteria. Annual Review of Biophysics and Bioengineering, 4: 119-136. https://doi.org/10.1146/annurev.bb.04. 060175.001003.

Browman, H.I., Cooke, S.J., Cowx, I.G., Derbyshire, S.W.G., Kasumyan, A., Key, B., et al. 2018. Welfare of aquatic animals: where things are, where they are going, and what it means for research, aquaculture, recreational angling and commercial fishing. International Council for the Exploration of the Sea Journal of Marine Science, 76: 82-92. https://doi.org/10.1093/icesjms/fsy067.

Caruana, R. 1997. Multitask learning. Machine Learning, 28: 41-75. https://doi.org/10.1023/a: 1007379606734.

Chatelle, C., Laureys, S., and Demertzi, A. 2016. Pain and nociception in disorders of consciousness. In Pain and the conscious brain. Edited by L. GarciaLarrea and P.L. Jackson. Lippincott Williams and Wilkins, Philadelphia, Pennsylvania, United States of America. Pp. 139-154.

Chiang, A.S., Lin, C.Y., Chuang, C.C., Chang, H.M., Hsieh, C.H., Yeh, C.W., et al. 2011. Threedimensional reconstruction of brain-wide wiring networks in Drosophila at single-cell resolution. Current Biology, 21: 1-11. https://doi.org/ 10.1016/j.cub.2010.11.056.

Chittka, L. and Niven, J. 2009. Are bigger brains better? Current Biology, 19: R995-R1008. https:// doi.org/10.1016/j.cub.2009.08.023.

Collett, M. and Collett, T.S. 2018. How does the insect central complex use mushroom body output for steering? Current Biology, 28: R733-R734. https://doi.org/ 10.1016/j.cub.2018.05.060.
Collin, G., Sporns, O., Mandl, R.C.W., and van den Heuvel, M.P. 2014. Structural and functional aspects relating to cost and benefit of rich club organization in the human cerebral cortex. Cerebral Cortex, 24: 2258-2267. https://doi.org/ 10.1093/cercor/bht064.

Corder, G., Ahanonu, B., Grewe, B.F., Wang, D., Schnitzer, M.J., and Scherrer, G. 2019. An amygdalar neural ensemble that encodes the unpleasantness of pain. Science, 363: 276-281. https://doi.org/ 10.1126/science.aap8586.

Dominguez, C., Hassan, H., and Crespo, A. 2017. Emotional robot control architecture implementation using FPGAs. Journal of Systems Architecture, 72: 29-41. https://doi.org/10.1016/j.sysarc.2016.08.004.

Dyer, F.C. 2002. The biology of the dance language. Annual Review of Entomology, 47: 917-949. https://doi.org/10.1146/annurev.ento.47. 091201.145306.

Eisemann, C.H., Jorgensen, W.K., Merritt, D.J., Rice, M.J., Cribb, B.W., Webb, P.D., and Zalucki, M.P. 1984. Do insects feel pain? A biological view. Experientia, 40: 164-167.

Eisenstein, E.M. and Carlson, A.D. 1997. A comparative approach to the behavior called 'learned helplessness'. Behavioural Brain Research, 86: 149-160. https://doi.org/10.1016/s0166-4328(96)02260-7.

Ellendersen, B.E. and von Philipsborn, A.C. 2017. Neuronal modulation of D. melanogaster sexual behaviour. Current Opinion in Insect Science, 24: 21-28. https://doi.org/10.1016/j.cois.2017.08.005.

Fiore, V.G., Dolan, R.J., Strausfeld, N.J., and Hirth, F. 2015. Evolutionarily conserved mechanisms for the selection and maintenance of behavioural activity. Philosophical Transactions of the Royal Society B-Biological Sciences, 370: 20150053. https:// doi.org/10.1098/rstb.2015.0053.

Franconville, R., Beron, C., and Jayaraman, V. 2018. Building a functional connectome of the Drosophila central complex. Elife, 7: e37017. https://doi.org/ 10.7554/eLife.37017.

Fuster, J.M. 2001. The prefrontal cortex - an update: time is of the essence. Neuron, 30: 319-333. https:// doi.org/10.1016/s0896-6273(01)00285-9.

Galili, D.S., Dylla, K.V., Ludke, A., Friedrich, A.B., Yamagata, N., Wong, J.Y.H., et al. 2014. Converging circuits mediate temperature and shock aversive olfactory conditioning in Drosophila. Current Biology, 24: 1712-1722. https://doi.org/10.1016/j.cub.2014.06.062.

Garcia-Larrea, L. and Bastuji, H. 2018. Pain and consciousness. Progress in Neuro-Psychopharmacology \& Biological Psychiatry, 87: 193-199. https:// doi.org/10.1016/j.pnpbp.2017.10.007.

Garcia-Larrea, L. and Jackson, P.L. 2016. Modeling pain experiences in the conscious brain: still not perfect but we are getting closer. In Pain and the conscious brain. Edited by L. Garcia-Larrea and P.L. Jackson. Lippincott Williams and Wilkins, Philadelphia, Pennsylvania, United States of America. Pp. xi-xiv. 
Gerhard, S., Andrade, I., Fetterig, R.D., Cardona, A., and Schneider-Mizell, C.M. 2017. Conserved neural circuit structure across Drosophila larval development revealed by comparative connectomics. Elife, 6: e29089. https://doi.org/10.7554/eLife.29089.

Grueber, W.B., Graubard, K., and Truman, J.W. 2001. Tiling of the body wall by multidendritic sensory neurons in Manduca sexta. Journal of Comparative Neurology, 440: 271-283. https://doi.org/10.1002/ cne. 1385 .

Guo, Y.M., Wang, Y.P., Wang, Q.X., and Wang, Z.R. 2014. The role of PPK26 in Drosophila larval mechanical nociception. Cell Reports, 9: 1183-1190. https://doi.org/10.1016/j.celrep.2014.10.020.

Gutfreund, Y. 2017. The neuroethological paradox of animal consciousness. Trends in Neurosciences, 40: 196-199. https://doi.org/10.1016/j.tins.2017.02.001.

Hagiwara, K., Perchet, C., Frot, M., Bastuji, H., and Garcia-Larrea, L. 2018. Insular-limbic dissociation to intra-epidermal electrical A delta activation: a comparative study with thermo-nociceptive laser stimulation. European Journal of Neuroscience, 48: 3186-3198. https://doi.org/10.1111/ejn.14146.

Hanesch, U., Fischbach, K.F., and Heisenberg, M. 1989. Neuronal architecture of the central complex in Drosophila melanogaster. Cell and Tissue Research, 257: 343-366. https://doi.org/10.1007/ bf00261838.

Hardcastle, V.G. 1997. When a pain is not. Journal of Philosophy, 94: 381-409.

Herculano-Houzel, S. 2012. The remarkable, yet not extraordinary, human brain as a scaled-up primate brain and its associated cost. Proceedings of the National Academy of Sciences of the United States of America, 109: 10661-10668. https://doi.org/ 10.1073/pnas.1201895109.

Herculano-Houzel, S., Mota, B., Wong, P.Y., and Kaas, J.H. 2010. Connectivity-driven white matter scaling and folding in primate cerebral cortex. Proceedings of the National Academy of Sciences of the United States of America, 107: 19008-19013. https://doi.org/10.1073/pnas.1012590107.

Hu, W.T., Peng, Y.Q., Sun, J.M., Zhang, F., Zhang, X.C., Wang, L.Z., et al. 2018. Fan-shaped body neurons in the Drosophila brain regulate both innate and conditioned nociceptive avoidance. Cell Reports, 24: 1573-1584. https://doi.org/10.1016/ j.celrep.2018.07.028.

Key, B. and Brown, D. 2018. Designing brains for pain: human to mollusc. Frontiers in Physiology, 9: 1027. https://doi.org/10.3389/fphys.2018.01027.

Kinoshita, M. and Homberg, U. 2017. Insect brains: minute structures controlling complex behaviors. In Brain evolution by design. Edited by S. Shigeno, Y. Murakami, and T. Nomura. Springer, Tokyo, Japan. Pp. 123-151.

Konig, C., Khalili, A., Ganesan, M., Nishu, A.P., Garza, A.P., Niewalda, T., et al. 2018. Reinforcement signaling of punishment versus relief in fruit flies. Learning \& Memory, 25: 247-257. https:// doi.org/10.1101/lm.047308.118.
Lee-Johnson, C.P. and Carnegie, D.A. 2010. Mobile robot navigation modulated by artificial emotions. Institute of Electrical and Electronics Engineers Transactions on Systems Man and Cybernetics Part B-Cybernetics, 40: 469-480. https://doi.org/ 10.1109/tsmcb.2009.2026826.

Liang, X., Hsu, L.M., Lu, H.B., Sumiyoshi, A., He, Y., and Yang, Y.H. 2018. The rich-club organization in rat functional brain network to balance between communication cost and efficiency. Cerebral Cortex, 28: 924-935. https://doi.org/10.1093/cercor/bhw416.

Lockwood, J. 2012. Killer empathy [online]. Radiolab, WNYCStudios. Available from wnycstudios.org/ story/185551-killer-empathy [accessed 4 July 2019].

Lu, C.B., Yang, T., Zhao, H., Zhang, M., Meng, F.C., Fu, H., et al. 2016. Insular cortex is critical for the perception, modulation, and chronification of pain. Neuroscience Bulletin, 32: 191-201. https://doi.org/ 10.1007/s12264-016-0016-y.

Maier, S.F. and Watkins, L.R. 1998. Stressor controllability, anxiety, and serotonin. Cognitive Therapy and Research, 22: 595-613. https://doi.org/10.1023/ a:1018794104325.

Marder, E. and Bucher, D. 2007. Understanding circuit dynamics using the stomatogastric nervous system of lobsters and crabs. Annual Review of Physiology, 69: 291-316. https://doi.org/10.1146/ annurev.physiol.69.031905.161516.

Marder, E., Goeritz, M.L., and Otopalik, A.G. 2015. Robust circuit rhythms in small circuits arise from variable circuit components and mechanisms. Current Opinion in Neurobiology, 31: 156-163. https:// doi.org/10.1016/j.conb.2014.10.012.

Markov, N.T., Ercsey-Ravasz, M.M., Gomes, A.R.R., Lamy, C., Magrou, L., Vezoli, J., et al. 2014. A weighted and directed interareal connectivity matrix for macaque cerebral cortex. Cerebral Cortex, 24: 17-36. https://doi.org/10.1093/cercor/bhs270.

Mather, J.A. 2011. Philosophical background of attitudes toward and treatment of invertebrates. Institute of Laboratory Animal Resources Journal 52: 205-212.

Matsunaga, N., Kuroki, A., and Kawaji, S. 2005. Superficial pain model using ANNs and its application to robot control. In IEEE/ASME International Conference on Advanced Intelligent Mechatronics, volumes 1-2. Edited by Institute of Electrical and Electronics Engineers, New York, New York, United States of America. Pp. 664-669.

McMackin, M.Z., Lewin, M.R., Tabuena, D.R., Arreola, F.E., Moffatt, C., and Fuse, M. 2016. Use of von Frey filaments to assess nociceptive sensitization in the hornworm, Manduca sexta. Journal of Neuroscience Methods, 257: 139-146. https:// doi.org/10.1016/j.jneumeth.2015.09.015.

Merker, B. 2007. Consciousness without a cerebral cortex: a challenge for neuroscience and medicine. Behavioral and Brain Sciences, 30: 63-81.

Mouraux, A. and Iannetti, G.D. 2018. The search for pain biomarkers in the human brain. Brain, 141: 3290-3307. https://doi.org/10.1093/brain/awy281. 
Niven, J.E. 2016. Neuronal energy consumption: biophysics, efficiency and evolution. Current Opinion in Neurobiology, 41: 129-135. https://doi.org/ 10.1016/j.conb.2016.09.004.

Niven, J.E. and Chittka, L. 2010. Reuse of identified neurons in multiple neural circuits. Behavioral and Brain Sciences, 33: 285. https://doi.org/10.1017/ s0140525x10001068.

Niven, J.E. and Laughlin, S.B. 2008. Energy limitation as a selective pressure on the evolution of sensory systems. Journal of Experimental Biology, 211: 1792-1804. https://doi.org/ 10.1242/jeb.017574.

Oh, S.W., Harris, J.A., Ng, L., Winslow, B., Cain, N., Mihalas, S., et al. 2014. A mesoscale connectome of the mouse brain. Nature, 508: 207-214. https:// doi.org/10.1038/nature13186.

Parisi, D. and Petrosino, G. 2010. Robots that have emotions. Adaptive Behavior, 18: 453-469. https:// doi.org/10.1177/1059712310388528.

Peng, F. and Chittka, L. 2017. A simple computational model of the bee mushroom body can explain seemingly complex forms of olfactory learning and memory. Current Biology, 27: 224-230. https://doi.org/10.1016/j.cub.2016. 10.054 .

Perry, C.J. and Baciadonna, L. 2017. Studying emotion in invertebrates: what has been done, what can be measured and what they can provide. Journal of Experimental Biology, 220: 3856-3868. https:// doi.org/10.1242/jeb.151308.

Perry, C.J., Barron, A.B., and Chittka, L. 2017. The frontiers of insect cognition. Current Opinion in Behavioral Sciences, 16: 111-118. https://doi.org/ 10.1016/j.cobeha.2017.05.011.

Pfeiffer, K. and Homberg, U. 2014. Organization and functional roles of the central complex in the insect brain. Annual Review of Entomology, 59: 165-184.

Purves, D., Augustine, G.J., Fitzpatrick, D., Hall, W.C., Lamantia, A.S., and White, L.E. 2012. Neuroscience. Sinauer, Sunderland, Massachusetts, United States of America.

Reggia, J.A., Katz, G.E., and Davis, G.P. 2018. Humanoid cognitive robots that learn by imitating: implications for consciousness studies. Frontiers in Robotics and AI, 5: 13. https://doi.org/10.3389/ frobt.2018.00001.

Sakaluk, S.K., Bangert, P.J., Eggert, A.K., Gack, C., and Swanson, L.V. 1995. The gin trap as a device facilitating coercive mating in sagebrush crickets. Proceedings of the Royal Society B-Biological Sciences, 261: 65-71. https://doi.org/10.1098/ rspb.1995.0118.

Seligman, M.E. and Maier, S.F. 1967. Failure to escape traumatic shock. Journal of Experimental Psychology, 74: 1-9. https://doi.org/10.1037/ h0024514.
Shih, C.T., Sporns, O., Yuan, S.L., Su, T.S., Lin, Y.J., Chuang, C.C., et al. 2015. Connectomics-based analysis of information flow in the Drosophila brain. Current Biology, 25: 1249-1258. https://doi.org/ 10.1016/j.cub.2015.03.021.

Skorupski, P., Maboudi, H., Dona, H.S.G., and Chittka, L. 2018. Counting insects. Philosophical Transactions of the Royal Society B-Biological Sciences, 373: 20160513. https://doi.org/10.1098/ rstb.2016.0513.

Sneddon, L.U., Elwood, R.W., Adamo, S.A., and Leach, M.C. 2014. Defining and assessing animal pain. Animal Behaviour, 97: 201-212. https:// doi.org/10.1016/j.anbehav.2014.09.007.

Stiehl, W.D., Lalla, L., Breazeal, C., and Institute of Electrical and Electronics Engineers. 2004. A "somatic alphabet" approach to "sensitive skin." In Proceedings of Institute of Electrical and Electronics Engineers International Conference on Robotics and Automation, volumes 1-5. Edited by Institute of Electrical and Electronics Engineers, New York, New York, United States of America. Pp. 2865-2870.

Strausfeld, N.J. 2012. Arthropod brains: evolution, functional elegance and historical significance. Harvard University Press, Cambridge, Massachusetts, United States of America.

van Swinderen, B. 2005. The remote roots of consciousness in fruit-fly selective attention? Bioessays, 27: 321-330. https://doi.org/ 10.1002/bies.20195.

Vogt, K., Schnaitmann, C., Dylla, K.V., Knapek, S., Aso, Y., Rubin, G.M., and Tanimoto, H. 2014. Shared mushroom body circuits underlie visual and olfactory memories in Drosophila. Elife, 3: 22. https://doi.org/10.7554/eLife.02395.

Waddell, S. 2013. Reinforcement signalling in Drosophila; dopamine does it all after all. Current Opinion in Neurobiology, 23: 324-329. https:// doi.org/10.1016/j.conb.2013.01.005.

Waddell, S. and Quinn, W.G. 2001. What can we teach Drosophila? What can they teach us? Trends in Genetics, 17: 719-726. https://doi.org/10.1016/ s0168-9525(01)02526-4.

Walters, E.T., Illich, P.A., Weeks, J.C., and Lewin, M.R. 2001. Defensive responses of larval Manduca sexta and their sensitization by noxious stimuli in the laboratory and field. Journal of Experimental Biology, 204: 457-469.

Yap, M.H.W., Grabowska, M.J., Rohrscheib, C., Jeans, R., Troup, M., Paulk, A.C., et al. 2017. Oscillatory brain activity in spontaneous and induced sleep stages in flies. Nature Communications, 8: 1815. https://doi.org/10.1038/s41467-017-02024-y.

Yarali, A., Niewalda, T., Chen, Y.C., Tanimoto, H., Duerrnagel, S., and Gerber, B. 2008. 'Pain relief' learning in fruit flies. Animal Behaviour, 76: 1173-1185. https://doi.org/10.1016/j.anbehav. 2008.05.025. 
Yeh, F.C., Panesar, S., Fernandes, D., Meola, A., Yoshino, M., Fernandez-Miranda, J.C., et al. 2018. Population-averaged atlas of the macroscale human structural connectome and its network topology. Neuroimage, 178: 57-68. https://doi.org/ 10.1016/j.neuroimage.2018.05.027.

Zhang, S.X., Miner, L.E., Boutros, C.L., Rogulja, D., and Crickmore, M.A. 2018. Motivation, perception, and chance converge to make a binary decision. Neuron, 99: 376-388. https://doi.org/10.1016/ j.neuron.2018.06.014.
Zheng, Z.H., Lauritzen, J.S., Perlman, E., Robinson, C.G., Nichols, M., Milkie, D., et al. 2018. A complete electron microscopy volume of the brain of adult Drosophila melanogaster. Cell, 174: 730-743. https://doi.org/10.1016/j.cell.2018.06.019. 